\title{
Analysis of erosion susceptibility for tungsten electrodes in submerged arc welding
}

\author{
Natala Astafeva ${ }^{1}$ \\ $\mathrm{PhD}$ in Engineering, Associate Professor, Department of \\ Engineering Technologies and Materials \\ Irkutsk National Research Technical University \\ Irkutsk, Russia \\ e-mail anstella@mail.ru
}

\author{
Anatoliy Astafev \\ Principal engineer Irkutsk Aviation Plant (IAP), \\ an affiliate of Irkut Corporation \\ Irkutsk, Russia \\ e-mail anatolliyas@mail.ru
}

\begin{abstract}
The article presents the results of studies on the influence of additives increasing stabilizing properties of the arc in the chemistry of tungsten electrodes on the erosion of their tips under SAW. Erosion and crown formation cause weld defects. Severe welding conditions are due to high temperatures of the tip in an enclosed volume. The influence of the chemistry of tungsten electrodes on the erosion wear and crown formation was identified. Lanthanum oxide $(0,8-1,4 \%)$, yttrium oxide $(2,4-3,5$ $\%)$ and pure tungsten electrodes were used for the experiments. The X-ray method was used to identify the presence of tungsten inclusions in Ti-Al-Zn weld joints. A thermal mechanical model describing the destruction of alloying metal electrodes and weld defect (tungsten inclusion) formation was developed. The experiments showed the possibility and efficiency of using pure tungsten electrodes under SAW based on the author's method involving stabilization of the arc discharge due to a special shielding gas feeding scheme
\end{abstract}

Keywords - TIG welding, gas tungsten arc welding, submerged arc, tungsten electrode erosion, titanium welds, inclusions

\section{INTRODUCTION}

For manufacturing titanium and titanium alloy parts, nonconsumable electrode arc inert gas welding methods are applied. A submerged arc welding (SAW) method is one of them [1-3]. This method is used in Russian aircraft production for manufacturing load-carrying structures with welds of up to $800 \mathrm{~mm}$ length and welded elements of up to $64 \mathrm{~mm}$ thickness. The method involves the immersion of the tungsten electrode into the pool crater until joint welds are completely penetrated.

These pressings are elements of aircraft basic structures. When producing such titanium alloy structures, either an electron-beam or a submerged arc welding method can be applied.

The advantage of the electron-beam welding process is larger penetration depth for one pass and a lower weld geometry factor. Their ratio under EBW is $0.2 \div 0.3$.

However, the SAW method is more efficient and technological. Both methods ensure high values of stability, low-cycle fatigue and impact viscosity of welded joints.
The sample of the titanium alloy workpiece is welded using the submerged arc welding method (see Fig. 1).
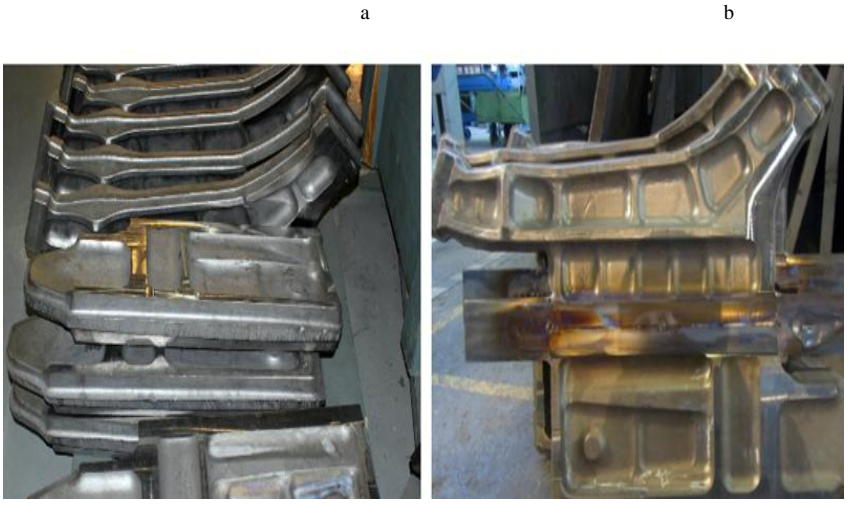

Fig. 1. The samples of the titanium alloy workpiece welded by submerged arc welding

$a$-pressings; $b$-welded joint of two pressings

With all advantages of the submerged arc welding method applied for thick-walled workpieces, one of its drawbacks is lowered resistance of tungsten electrodes. The arc burns in a closed space and the tip is under increased temperature loads. It causes erosion of the tip and formation of a crown above this area. The erosion leads to the destruction of the tungsten electrode and penetration of tungsten inclusions into the melt pool.

For the SAW process, lanthanum / yttrium oxide electrodes are used. Alloying additives improve emission capacities of the electrode, reduce a cathode voltage drop and improve the agitation process $[9,10]$.

The studies [3-10] showed the influence of different factors on the electrode resistance and erosion during the SAW process, described methods which can bes used to increase the life of tungsten electrodes. In particular, the authors [4, 5] argue that an increase in $\mathrm{LaO}$ or $\mathrm{Y}_{2} \mathrm{O}_{3}$ in the chemical composition of tungsten electrodes during the SAW process increases their resistance. 
Finishing tungsten electrodes have never been used in SAW due to their low heat resistance and technical specifications.

However, increased heat resistance of EVI-1, EVI-2 and EVL electrodes cannot prevent erosion of the tip and formation of crowns.

The research is relevant due to the need for decreasing the share of parts containing tungsten inclusions. It makes it possible to increase the quality of joint metal with pre-set mechanical and physical and chemical properties which can improve the reliability of high-loaded titanium structures. Besides, the production cycle will decrease due to no need for eliminating tungsten inclusions.

\section{MATERIALS AND METHODS}

To study the impact of $\mathrm{LaO}$ or $\mathrm{Y}_{2} \mathrm{O}_{3}$ in tungsten electrodes applied for the SAW process on the erosion of the tip and formation of crowns, titanium alloy samples of $64 \mathrm{~mm}$ thickness and $500 \mathrm{~mm}$ length were produced. The approximate chemical composition of the alloy is presented in Table 1 [11].

TABLE I. APPROXIMATE CHEMICAL COMPOSITION OF THE ALLOY

\begin{tabular}{|l|l|c|c|c|c|}
\hline Element & \multicolumn{1}{|c|}{$\mathbf{T i}$} & $\mathbf{C}$ & $\mathbf{F e}$ & $\mathbf{M o}$ & $\mathbf{V}$ \\
\hline $\begin{array}{c}\text { Content } \\
(\%)\end{array}$ & $85,15-91,4$ & $\begin{array}{c}\text { less } \\
\text { than } \\
0,1\end{array}$ & $\begin{array}{c}\text { less } \\
\text { than } \\
0,15\end{array}$ & $0.5-2$ & $\begin{array}{c}0,8- \\
2,5\end{array}$ \\
\hline Element & \multicolumn{1}{|c|}{$\mathbf{F e}$} & $\mathbf{A l}$ & $\mathbf{Z r}$ & $\mathbf{O}$ & $\mathbf{N}$ \\
\hline $\begin{array}{l}\text { Content } \\
(\%)\end{array}$ & $\begin{array}{l}\text { less than } \\
0,25\end{array}$ & $5,5-7$ & $\begin{array}{c}1.5- \\
2,5\end{array}$ & $\begin{array}{l}\text { less } \\
\text { than } \\
0,15\end{array}$ & $\begin{array}{l}\text { less } \\
\text { than } \\
0,05\end{array}$ \\
\hline
\end{tabular}

Ring-sharpened lanthanum / yttrium oxide electrodes SVI1, EVI-2, EVL (Government Standard 23949-80, Technical Conditions 48-19-27-88) and EVCh tungsten electrodes without alloying additives were (Government Standard 2394980 ) of $10 \mathrm{~mm}$ in diameter were used in the SAW process. The shape and dimensions of the tip are shown in Fig. 1. The chemical composition of electrodes was tested using BRUKER S8 TIGER. The evidence of $\mathrm{LaO} 0,8-1,4 \%$ (from 0,8 to 1,4 ), of $\mathrm{Y}_{2} \mathrm{O}_{3}$ (from 1,5 to 2,3)\% [12]. Tungsten inclusions in joints was identified using PHILIPS MG 452 (see Fig. 2).

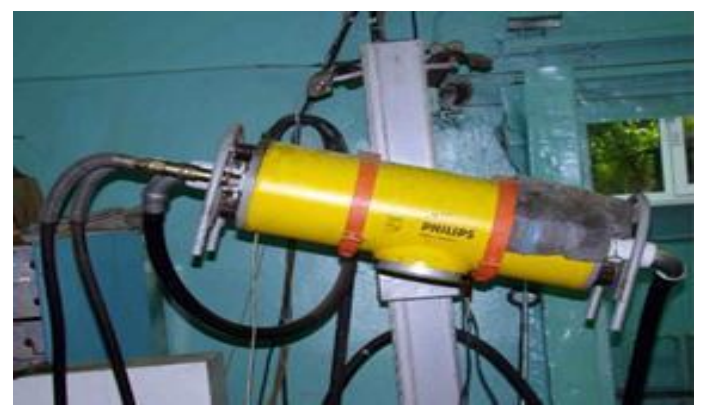

Fig. 2. The x-ray machine.
Two-sided welding of butt joints was carried out using a GSPD-1M by the scheme described in [2] using the method developed by the author [3]. Key parameters of welding modes are presented in Table 2 .

TABLE II. TIG WELDING PARAMETERS

\begin{tabular}{|c|c|c|c|c|}
\hline $\begin{array}{c}\text { mode } \\
\text { options }\end{array}$ & $\begin{array}{c}\text { Current } \\
\text { (A) }\end{array}$ & $\begin{array}{c}\text { Penetration } \\
\text { of the W-th } \\
\text { electrode } \\
\text { (mm) }\end{array}$ & $\begin{array}{c}\text { Helium } \\
\text { consumptio } \\
\text { n (l/min) }\end{array}$ & $\begin{array}{c}\text { Argon } \\
\text { consumpti } \\
\text { on (l/min) }\end{array}$ \\
\hline value & 1700 & 17 & 20 & 24 \\
\hline $\begin{array}{c}\text { mode } \\
\text { options }\end{array}$ & $\begin{array}{c}\text { Arc } \\
\text { voltage } \\
(\mathbf{V})\end{array}$ & $\begin{array}{c}\text { Welding } \\
\text { rate (m/h) }\end{array}$ & $\begin{array}{c}\text { Cooling } \\
\text { water } \\
\text { temperature } \\
\left({ }^{\circ} \mathrm{C}\right)\end{array}$ & $\begin{array}{c}\text { Seam } \\
\text { protection } \\
(\text { l/min) }\end{array}$ \\
\hline value & $14-15$ & 4 & $20-23$ & 8 \\
\hline
\end{tabular}

The submerged arc welding method involves feeding and formation of several annular flows of shielding gases enveloping the arc. Arc plasma forming, stabilizing and shielding gas is fed by three separate jet streams simultaneously. Annular flows are formed by moving them around the electrode axle in a spiral mode in one direction with different torsion angles and gas-flow rates. Gas is rotated around the axle with increase in a velocity rate from the internal to the external flow. The external shielding flow is directed with a shield cup around the weld pool (see Fig. 3).

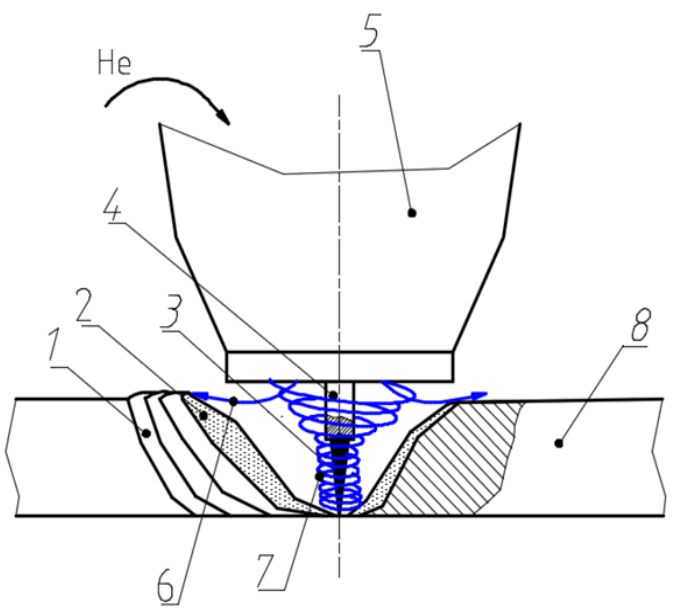

Fig. 3. A SAW scheme with several flows of shielding gas enveloping the $\operatorname{arc}$

1 - weld seam; 2 - weld pool; 3 - submerged arc; 4 -the electrode is tungsten; 5 - shield cup, 6 -gas protective; 7 -arc forming gas; the product is welded

After completion of the welding process, the flows are checked in the following sequence: first, the arc plasma forming and stabilizing flow is checked, then the external shielding flow is checked. 
To protect the weld pool and stabilize the arc, high-purity helium was used. To protect the weld face and back, argon was used.

The welding process was followed by heat treatment in the furnace under the following conditions: heating temperature $700^{\circ} \mathrm{C} \pm 10^{\circ} \mathrm{C}$ soaking time $\mathrm{t}=2 \mathrm{~h} 30 \mathrm{~min}$, air cooling up to the inside temperature.

The cyclogram of the SAW process is shown in Fig. 4.

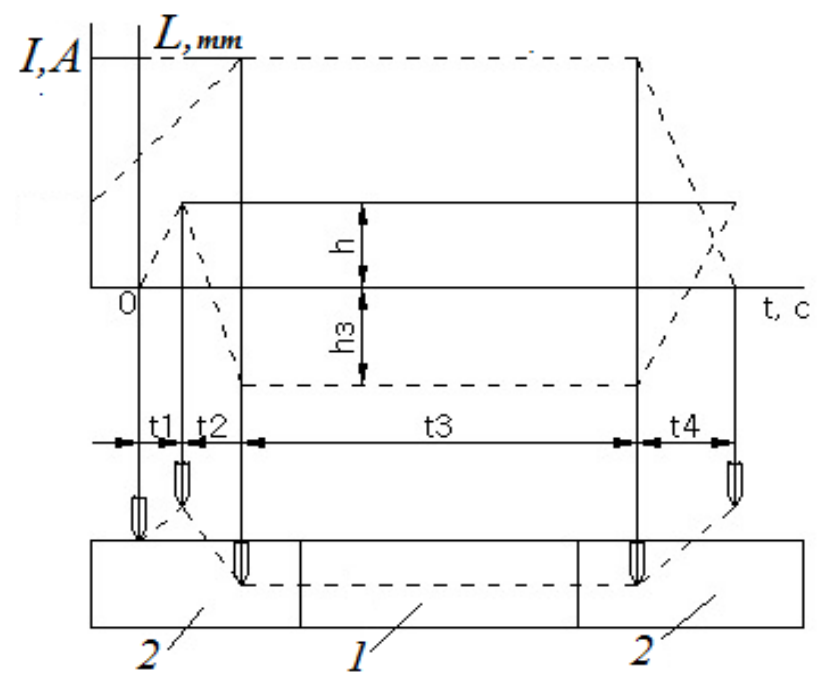

Fig. 4. Cyclogram of the SAW process

1 - main metal; 2 - run-in-run-off plate; $h$ - arc extension value; $t_{l}$ - arc striking period; $t_{2}$ - electrode is lowered and put deeper; $h_{3}$ - pre-set level of electrode deepening; $t_{3}$ - welding period; $t_{4}$-electrode leaving the weld pool; $I-$ working value of the welding current.

\section{RESULTS AND DISCUSSION}

During the SAW process under the described conditions, it was identified that in samples produced using yttrium electrodes $\mathrm{Y}_{2} \mathrm{O}_{3}$ (from 1,5 to 2,3)\%, there are tungsten inclusions. According to the X-ray film, tungsten is located uniformly along the weld (see Fig. 5).

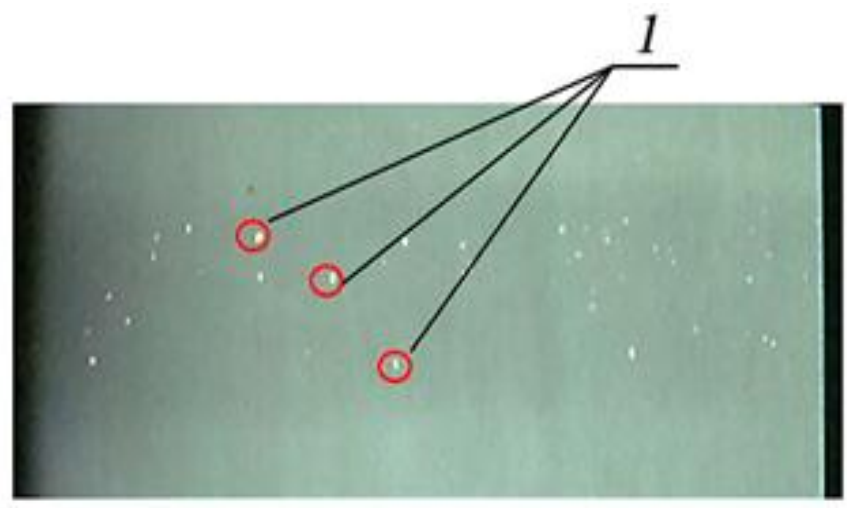

Fig. 5. The result of X-ray inspection of welds, $1-$ tungsten inclusions.
In all cases, the electrodes are susceptible to erosion under the SAW conditions (see Fig. 6). When welding using 1,4\% lanthanum oxide electrodes (Government Standard 23949-80), an insignificant amount of tungsten inclusions was found.

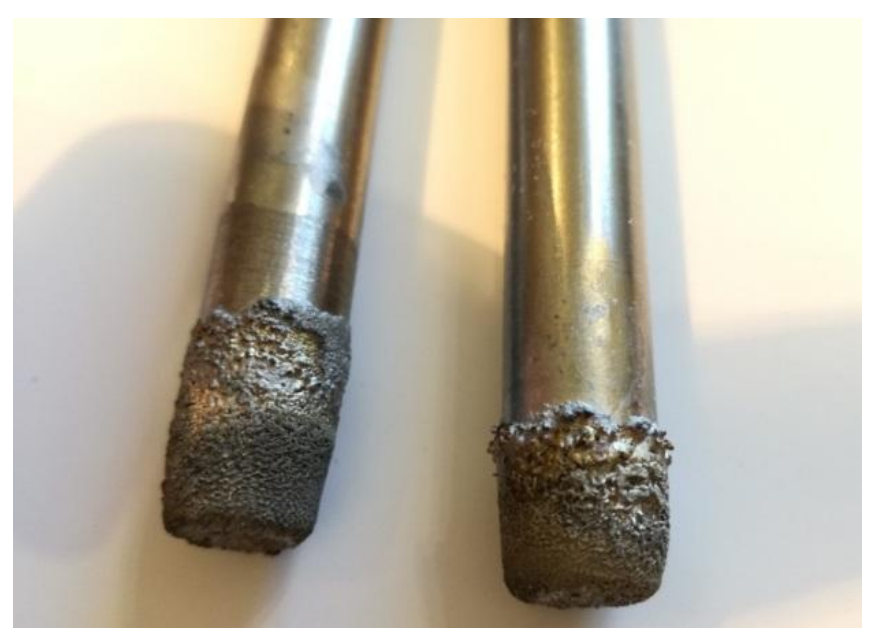

Fig. 6. EVL electrodes after the primary use for the SAW

EVL tungsten electrodes containing $0,8-1,1 \% \quad \mathrm{LaO}$ (Technical Conditions 48-19-27-88) are much more resistant to tip erosion. In their weld, an insignificant amount of tungsten inclusions was found.

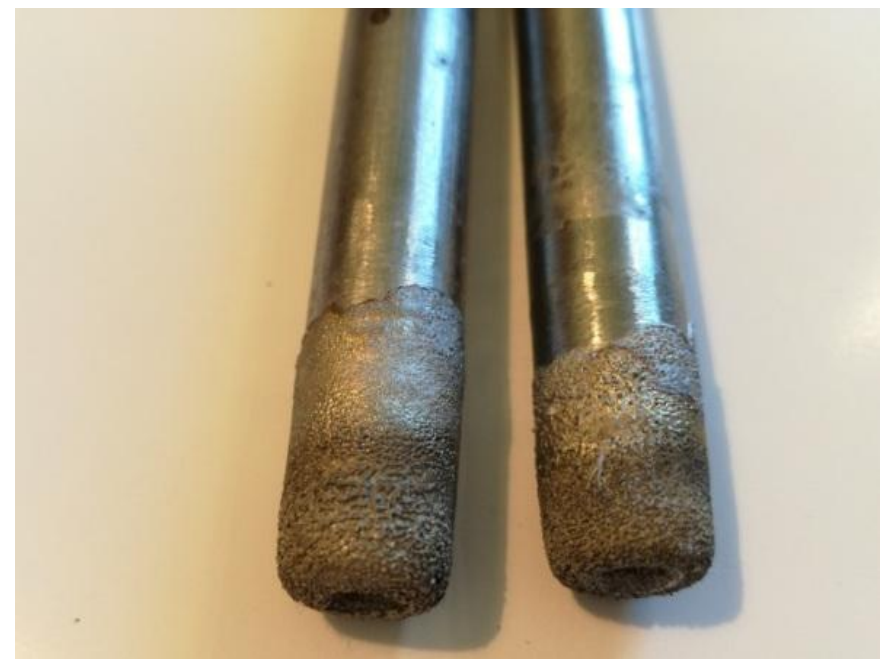

Fig. 7. Grinded EVL electrodes after the secondary use for the SAW

With the secondary use of these electrodes which were preliminarily grinded, the erosion level decreased, the number of crowns became smaller, and tungsten inclusions in welds were not found.

Pure tungsten electrodes EVCh (without alloying additives) showed the best results. Under the same SAW conditions, there was no tip erosion (see Fig. 7). The X-ray control did not identify such weld defects as tungsten inclusions. 
Average values of the experiment results are shown in Fig. 8. The tip erosion was estimated on a scale from one to ten. Five corresponded to the worst state of the tip (the highest degree of erosion, the crown formed along the outline of the electrode as shown in Fig. 8).

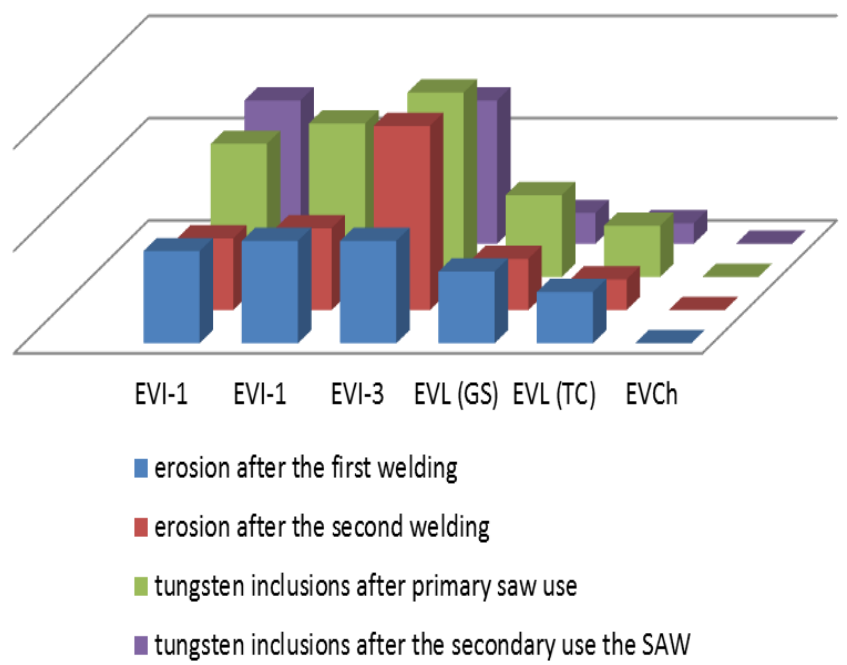

Fig. 8. Average values of the experiment results

Do not use the word "essentially" to mean "approximately" or "effectively." Based on the studies of the SAW process [13-22] and the tests, a thermomechanical model of electrode destruction and weld defect formation was developed. It can be presented as follows.

At a working zone temperature of $2850 \mathrm{~K}$, lanthanum and yttrium oxides are reduced. Exploding lanthanum and yttrium vapor carries away tungsten particles which forms voids (erosion) in metal. High lanthanum or yttrium pressure contributes to their rapid elimination from the electrode surface (see Fig. 9).

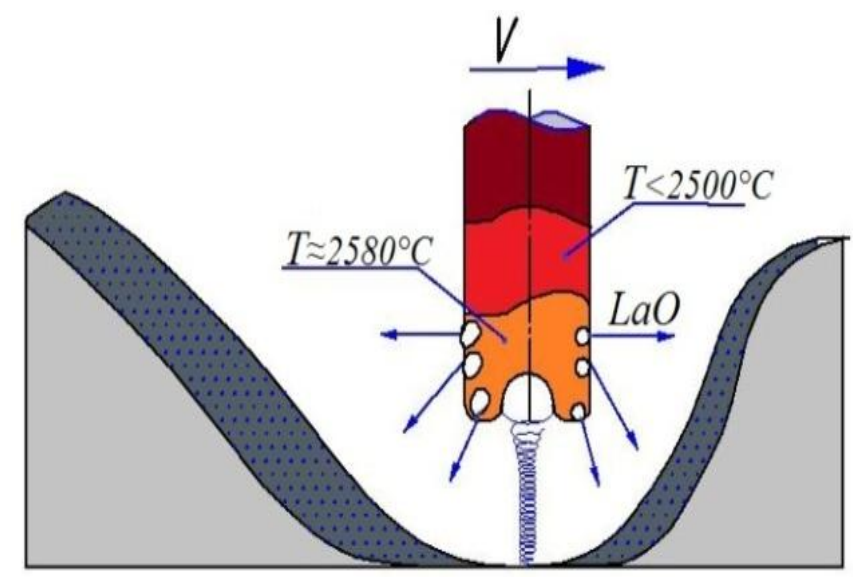

Fig. 9. The model of the first stage - lanthanum oxide reduction

As a result of the cathode dispersion, tungsten particles escape the electrode field and its emissive part forming oversaturated concentration around the electrode. Combining with oxygen which can be present in $\mathrm{He}$ in welded metal and on welded edges in the form of harmful impurities, the particles form $\mathrm{WO}_{2}$ and $\mathrm{WO}_{3}$. The boiling temperature of oxides is twice less than the melting temperature of tungsten (see Fig. 10).

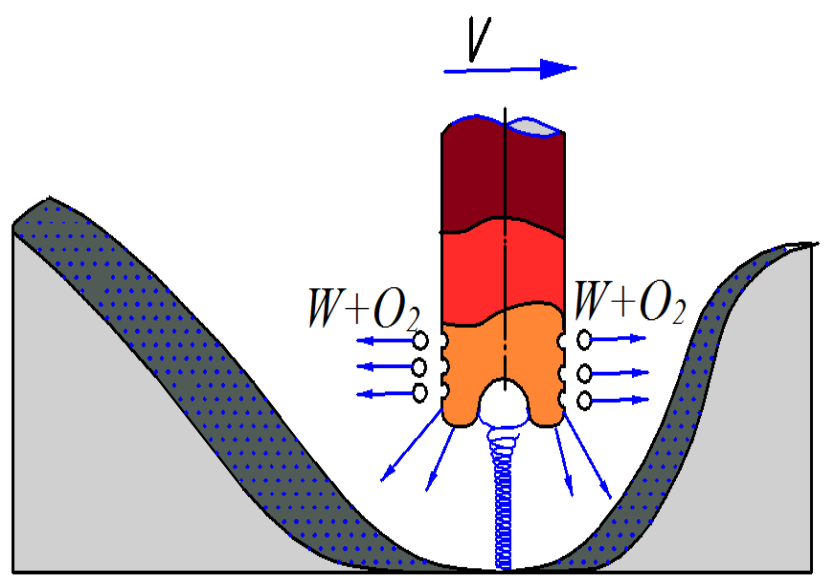

Fig. 10. The model of the second stage - tungsten oxide formation and settling of drop compounds in cold areas of the electrode.

Tungsten oxides evaporate. Their volume increases more than thrice in comparison with the tungsten volume. Along with titanium alloy vapor, tungsten oxides form drop compounds. These compounds settle in cold zones of the electrode above the erosion zone forming asymmetrical crowns (see Fig. 11 ).

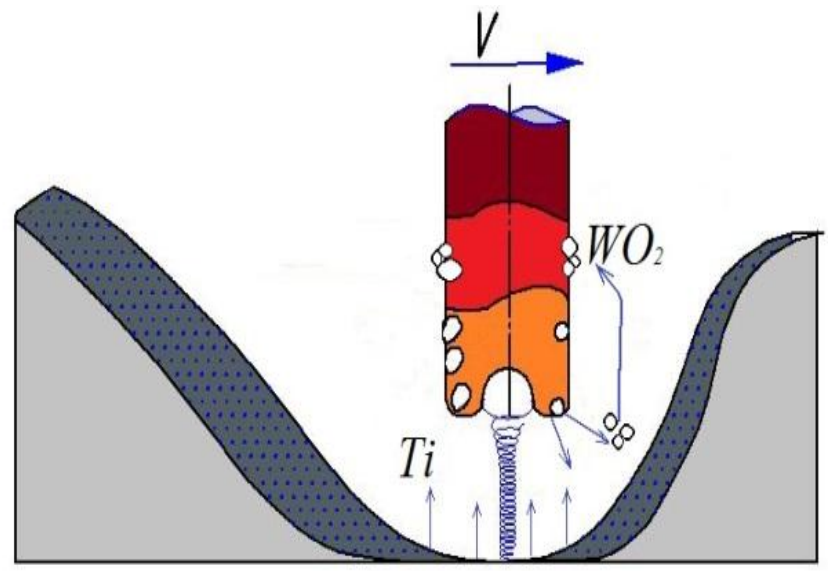

Fig. 11. The model of the third stage - drop compound formation

Under gravity and welding arc vibration, some drop compounds fall off into liquid metal of the weld pool. Other compounds, not being able to settle, fall into the weld pool as well (see Fig. 12 ).

Thus using the research results, the stages of the process reflecting the mechanism of destruction of lanthanum oxide 
tungsten electrodes in the submerged arch welding of thickwalled titanium structures were described.

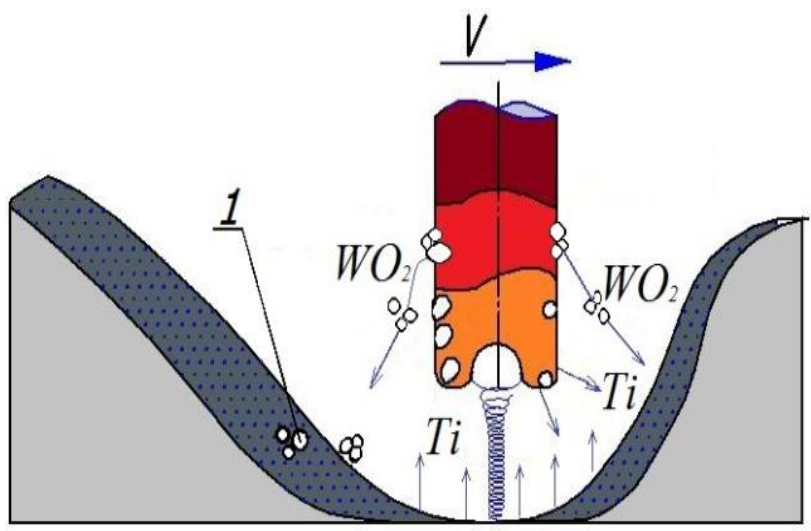

Fig. 12. The model of the fourth stage - penetration of drop compounds into metal of the molten pool:

1 - tungsten inclusions

\section{CONCLUSION}

Thus, under the SAW conditions, while joining long parts with thick edges when the electrode is penetrated into weld metal to a depth of 15-20 mm, EVL and EVI electrodes with increased heat resistance and stabilizing properties are susceptible to significant erosion and formation of crowns. Under gravity and welding arc vibration, the particles of the crown fall into the melt pool forming weld defects.

The developed model describes alloy-containing electrode destruction and weld defect formation.

When testing tungsten electrodes by the author's SAW method, involving stabilization of the arc discharge due to a special shielding gas feeding scheme, only tungsten electrodes without alloying additives were not susceptible to tip erosion and crown formation which speaks for the presented mechanism of the thermomechanical model.

The feed of shielding gas by several shielding flows enveloping the electrode and the arc increases the opportunities of the SAW method, stabilizes the arc and increases the penetration depth at a smaller deepening value, in this case, pure tungsten can be used as electrodes.

The experiments showed the possibility and efficiency of using pure tungsten electrodes under SAW based on the author's method involving stabilization of the arc discharge due to a special shielding gas feeding scheme.

\section{References}

[1] N.A. Astafeva, "Welding and closely related technologies in aircraft building", in Aircraft building and transport of Siberia: Proc. of the 6th All-Russian Sc. Conf., Irkutsk, 2016, pp. 67-72.
[2] A.G. Astafev, N.A. Astafeva, "Production of titanium strong frames by means of submerged arc welding", Welding in Siberia, vol. 12, pp. 6-8, 2003

[3] A.G. Astafev, Tungsten submerged arc welding, RF Patent 2182061 V23K9/167, 2000111617/02 (2002)

[4] B.I. Dolotov, M.D. Cherepanov, "Calculation of a hemicylindrical arc of the toroidal electrode", Welding production, vol. 4, pp. 3-5, 2002

[5] B.I. Dolotov, V.I. Muravyev, B.I. Maryin, and Y.L. Ivanov, "Highe resistant tungsten electrodes", Welding production, vol. 10, pp. 23-26, 1996.

[6] M.D. Cherepanov, B.I. Dolotov, and V.I. Muravyev, "Changes in geometry of the tungsten electrode arc under the own electromagnetic field", Welding production, vol. 6, pp. 3-5, 2000

[7] S.S. Fedorov, M.Y. Tishchenko, S.V. Shmakov, S.A. Zajdes "Features of welding of highly loaded structures made of titanium alloys", Welding production, vol. 3, pp. 16-21, 2016

[8] B.I. Dolotov, "Erision resistance of tungsten electrodes in high curren welding arcs", in Material engineering of higher-melting compounds. Achievements and challenges: Proc. of the Int. Sc. Conf., Kiev, May 27 29, 2008, p. 152.

[9] L.M. Percitz, M.S. Gritsenko, and A.R. Sidorov, "Evaluation of factors influencing the long resistance of tungsten electrodes and reliability of arc agitation during the gas tungsten arc welding process", Welding in nuclear technology, vol. 1, pp. 14-16, 1979.

[10] B.I. Dolotov, Improvement of efficiency of gas tungsten welding of frame and panel titanium structures of aircrafts, Komsomolsk-na-Amure, 2010 .

[11] A.A. Ilyin, B.A. Kolachev, and I.S. Polkin, "Titanium alloys Composition, structure, properties: Reference book", Moscow, VI-AS MATI, 2009.

[12] GOST 23949-80 a tungsten non-consumable welding Electrodes. Technical conditions. Information on http://docs.cntd.ru/document/1200004880

[13] B. I. Dolotov, Improvement of efficiency of processes of welding with tungsten electrode in inert gases the titanium beam and panel structures of aircraft, Moscow, 2010

[14] A.V. Konovalov, A.S. Kurkin, E.L. Makarov, V.M. Nerovny, and B.F. Yakushin, Theory of welding processes: a course book for universities. Moscow, MSTU, 2007.

[15] V.V. Redchitz, "Analytical evaluation of probability of welding gas bubbles formation", Automatic welding, vol. 9, pp. 32-35, 1983.

[16] V.V. Redchitz, G.D. Nikiforov, "Kinetics of gas bubble growth in weld pools, Physics and chemistry of material processing", vol. 2, pp. 123 130, 1977.

[17] B.I. Dolotov, V.I. Muravyev, and B.I. Maryin, "Mixture of metal in weld pools during the tungsten submerged arc welding", Welding production, vol. 2, pp. 15-16, 1998.

[18] V.I. Merkulov, A.G. Bratukhin, "Peculiarities of welding of high responsible aircraft titanium structures", Aviation industry, vol. 1, pp. 43-48, 2000.

[19] V.V. Anisimov, V.A. Bukarov, "Evaluation of the heat balance of tungsten electrodes during the argon tungsten welding process", Issues of nuclear science and technology, vol. 9, pp. 31-39, 1989.

[20] S. Katayama, M. Mizunal, and A. Matsunaeva, "Liquid flow inside molten pool during TIG welding and formation mechanism of bubble and porosity", in Proceedings of the 7th Int. Welding Symp., Kobe, Yapan Welding Soc, pp. 125-130, 2001.

[21] M. Tanaka, M. Ushlo, and J.J. Lowke, "Numerical analysis for weld formation using free-burning helium arc at atmospheric pressure", JSME Int. Journal Series, vol. 3, pp. 397-404, 2005.

[22] V.S. Mechev, A.E. Eroshenko, "Parameters of the arc column near the part during the argon tungsten arc welding", Automatic welding, vol. 1, pp. $25-30,1984$ 